\author{
Hatice İrem EKER \\ Arş. Gör.| Res. Assist. \\ Ondokuz Mayis Üniversitesi, Fen Edebiyat Fakültesi, Felsefe Bölümü, Samsun-TÜRKIYE \\ Ondokuz Mayis University, Faculty of Sciences and Letters, Department of Philosophy, Samsun-TURKEY \\ Orcid ID: 0000-0003-0903-7515 \\ e-mail: h.iremeker@gmail.com
}

\title{
Platon Felsefesi’nde Sanat Eleştirisine Giden Yol ya da Gölgeye Gölge Diyebilme İmkânı Öz
}

Felsefi tarihte büyük rolü olan Platon, felsefi düşünsel gelişime en büyük katkıyı epistêmê ile dóksa olarak adlandırdığı bilgi türleri arasındaki ayrımı gözetmekle yapmıştır. İlk sistemli diyalektikçi olan bu ustanın kavramlar arasındaki ayrımı yaparken izlediği düşünsel yol, bugün hâlen gerçek olan ile sadece sanıya dayanan bilgi türleri arasında ayrım yapmaya çalıştı̆̆ımızda önümüzde bir rehber olarak bulunmaktadır. Bu diyalektik rotayı canlı tutmak adına bu çalışmada, Platon düşüncesindeki sanat kavramının incelenmesi hedeflenmiştir. Platon'un sanat kavramını incelerken, Platon'a yöneltilen 'sanat ve sanatçı karşıtı' olma iddiasını güncel bir problem olarak ele alarak, onun düşüncesinde karşı çıktığı olgunun genelde sanatın kendisi değil, gerçek olmayan e.d. doksa türü bilgiyi içeriği olarak alan tikel bir sanat türü olduğu aktarılmaya çalışıldı. Bu hedef doğrultusunda, birinci başlık kapsamında Platon'un çağında yer alan sanat etkinliğine bir göz atıldı. İkinci başlık kapsamında, Platon'un bilgikuramında epistêmê ile doksa arasında yaptığ1 ayrım kısaca incelendi. Üçüncü başlık kapsamında, retorik, sofistlerin sanatı olarak incelendi. Dördüncü başlık kapsamında, taklit, tragedya oyuncusunun sanatı olarak betimlendi. Her iki sanat türünde de Platon'un işaret ettiği ortak özellik, doksa türü bilgiyi içerikleri olarak taşımalarıdır. Böylelikle Platon'un sanat eleştirisinin temelinde yatanın genelde sanat değil, doksa türü bilgiyi içeriği olarak alan ve toplumda yayılmasında işlevselliği olan özel ve tikel bir sanat biçimi olduğunu gösterildi.

Anahtar Kelimeler: Epistêmê, Doksa, Diyalektik, Sanat, Tékhnê.

\section{The Way Towards Critique of Art in Plato's Philosophy or the Possibility to Call Shadow as Shadow}

\begin{abstract}
Plato, who had played a great role in philosophical history, had a great effect on the development of philosophical thinking through evaluating the differences between the knowledge types that he called epistêmê and doksa. The intellectual way of him while he was setting the conceptual differentiation between these concepts, still stands there as a guide for us whenever we try to make a division between true knowledge and just an opinion. In order to keep alive this dialectical route, the target is determined to examine the concept of art in Plato's philosophy in this paper. While handling the concept of art, the paper is focused on the general judgment that 'Plato was an opponent of art and artist' and is tried to show what he opposed is not the art itself but rather the knowledge type which is called as 'doksa'. In accordance with this target, in the first chapter, a glance at the art activities in Plato's age is taken. In the second chapter, the difference between epistêmê and doksa in Plato's epistemology is inquired briefly. Plato called the knowledge type which is based on the appearances as doksa, while he called the knowledge type which is conceived through reason by the process of dialectical investigation as epistêmê. In the third chapter, it is analysed that the rhetoric as sophists' art. In the fourth chapter, it is described that mimesis as the tragedy actor's art. The common feature of these arts which Plato had addressed is that both of them include doksa as their content. Thus, it is presented what Plato had reviewed is not the art in general, but rather the specific and particular type of art which includes knowledge type doksa.
\end{abstract}

Keywords: Epistêmê, Doxa, Tékhnê, Art, Dialectic.

\section{Giriş}

Bilim dallarının içinden göçüp gittiği zamanlardan beri felsefe, herhalde en çok çağlarca tekdüze aktarılan yargılardan mustariptir. Felsefeyle ilgilenen hemen hemen herkes 'düşünürleri 
kendi çağlarındaki koşullarla birlikte değerlendirmek gerektiğini’ duysa, hatta söylese bile bu tür bir düşünme sisteminin oturabilmesi güçlü bir uğraşı istemektedir. Felsefeyle ilgilenen herkes hayatında en az bir kez şöyle bir yargıyla karşılaşır: 'Platon sanat ve sanatçı düşmanıdır' yahut 'Platon sansürcüdür.' Herhalde bu yarg1, Platon metinlerinin bir değerlendirmesinden kolayca çıkarılamaz. Kavramsal ayrımları ve genel olanla bu ayrımların ilintisini aramak felsefecinin başlıca görevlerinden birisi olduğunu söyleyebiliriz. Eğer dönemsel koşulları içerisinde bir filozofu değerlendirmek istiyorsak, bütün yapabileceğimiz, onun düşüncelerini dayandırdığı nedenleri irdelemek ve kavramsal ayrımlarını hangi gerekçelere dayanarak yaptığını takip etmek, eleştiriyi bu gerekçelere yönlendirmek olacaktır. Bu nedenle, bu yarg1 belirlenimini- bahsettiğimiz önyargıy halen güncelliğini yitirmemiş bir problem olarak değerlendirerek konuyu biraz daha ayrıntılı olarak ele almayı amaçlıyoruz. Böylelikle, Platon'un sanat ve sanatçıya yönelttiği eleştirileri, sanat/tékhnêe, retorik/rhetorik, taklit/mimêsis, tragedya kavramları üzerinden irdeliyorum. Bu irdeleme böylelikle temel olarak şu soruyu takip edecektir; Platon'un eleştirisinin muhatabı genelde sanat yahut sanatçı mıdır? Bu sorunun cevabına biraz daha ayrıntılı bir biçimde yaklaşabilmek için öncelikli olarak ilk başlıkta Platon çağında sanatı ifade eden örneklere bir göz atacağız. İkinci başlıkta Platon'un bilgikuramına kısa bir bakış atarak, epistêmê ile doksa arasında yaptığı ayrımın gerekçelerini ve içeriğini inceleyeceğiz. Üçüncü ve dördüncü başlıklarda Antik Yunan sosyal yaşam, kültür ve eğlencesinin iki önemli öğesi olan sofistler ve tragedya oyuncuları ile onların sırasıyla sanatlarını ifade eden retorik ve taklidin toplumsal işlevlerini hatırlatacağız. Platon, her iki sanat türünde de ortak olan tek bir şeyi karşısına almışır. Hem tragedya oyuncusu hem de sofist farklı sanat biçimleri altında da olsa gerçeğe ilişkin bilgi epistêmêyi değil, görünüşe ilişkin ve genel kanılardan oluşan sorgulanmamış bilgi türü doksayı yaygınlaştırmakta ve bunları gerçeklermiş gibi göstermektedirler. Böylelikle, umuyorum ki, sorunun cevabı tekdüzeliğinden biraz olsun arınacak ve Platon'un eleștirisinin muhatabının genelde sanat değil, bilhassa içeriği sorgulanmamış genel kanılardan oluşan ve bu kanıları gerçeklermiş gibi gösteren tikel sanat türleri olduğu gösterilebilecektir.

\section{Tarihsel Arka Plan}

Batı tarihinde ilk filozoflar olarak anılan Eski Yunan düşünürlerinde gelişen düşünme biçiminin, kozmosu ve toplumsal ahlaki-siyasi yaşamı yöneten güçleri, Tanrılara atfeden mitolojik hikâyelerden, bu gücü kozmosun kendisinde aramaya yönelten bir düşünüş biçimine ${ }^{1}$ dönüşme sürecinin başlangıcı olduğu ifade edilse de, hemen tüm düşünsel ve yaşamsal biçimleri kuşatan bir dönüşüm değildir bu. Oyunlar, halk deyişleri, epik anlatılar vs. gibi kültür ögelerinde Homeros destanları ve Tanrıların kozmosu ve toplumsal yaşamı yönlendiren etkinliklerini konu edinen mitolojik anlatıların etkisi sürer. Pre-Sokratik felsefede Thales, Anaximenes, Anaximandros, Herakleitos gibi filozoflar, ağırlıklı olarak düşüncelerini söylencesel unsurlarla bezeyerek ve şïrsel dil ile aktarırlar. Hem Sokrates'in (MÖ 469? - MÖ 399?) sokak söyleşilerini bizlere aktaran hem de kendi bilgi kuramını Sokrates'in diyalog biçimini koruyarak inşa eden Platon'un (MÖ 429? - MÖ 347?) dilinde mitoslara yer vermesinin, felsefi gerçekliğin içinde hâlâ efsane gücü bulunduğunun kanıtı olduğuna ilişkin yorumlara rastlamakla birlikte, ${ }^{2}$ mitolojik söylencelerden farklı olarak Platonik mitosların, kendi felsefesini aktarabilmek için kullandığı simgesel araçlar olduğunu söylemek mümkündür. ${ }^{3}$ Aradaki fark mitolojik söylencelerin kültürel olarak yayg1n bir inanc1 kapsıyor olması ancak, Platon'un kullandığı mitoslara ait imgelerin, filozofun düşüncelerinin simgeleri olarak kurgulanmış olmasındadır (A ğaoğulları, 2009: 55). İnanç öğelerinin, simgelere dönüşümü felsefi dilin oluşma sürecinde sayılabilir. Platon’un öğrencisi olan Aristoteles’in (MÖ 384

\footnotetext{
${ }^{1} \mathrm{Bu}$ düşünüş biçimindeki dönüşüme ilişkin tarihsel bir okuma için bkz. (Şenel, 2004) ve (Ağaoğulları, 2009). Mitolojik düşünüşte “doğa güçleri canlı varlıklar (tanrılar); insan-doğa, insan-insan ilişkileri ve doğal olaylar, tanrıların düşüncelerinin ve eylemlerinin ürünü görülerek birtakım mitoslarla açıklanmaya çalışlır” (Şenel, 2004: 123).

2 Ağaoğulları, Châtelet’ten aktar1yor (Ağaoğulları, 2009: 55).

${ }_{3}^{3}$ Ağaoğulları Cassirer'den aktarıor (Ağaoğulları, 2009: 55).
} 
- MÖ 322) dilinin ise artık mitoslar barındırmadığını söyleyebiliriz. Ancak, her iki filozofun da ortak yaşam tecrübesinde mitolojiye ait söylencelerin aktarılma biçimlerinden biri olarak önemli bir yer tutan, ağırlıklı olarak Homeros destanlarından esinlenilerek sahneye konulan, başrollerini mitolojide yer alan Tanrıların, kahramanların vs. paylaştığı tragedya/tragöidia bulunur. Eski Yunan tragedyaları, Batı'da tiyatronun tarihsel kökenlerini, mitolojiye ait düşünüşün izlerini ve daha da önemlisi felsefeyi mitolojiden ayıran dilsel dönüşümü takip etmek açısından önem taşır. Platon ve Aristoteles'in de genel olarak sanatın, özel olarak da o dönemde birbirinden pek ayrılamayan şïr ve tragedyanın toplumsal yaşamdaki yerini, işlevini ve mahiyetini araştırma nesnesi olarak aldıklanı görülür. Elimize bir kısmı ulaşan Poetika, Aristoteles tarafından teknik bir biçimde şiir ve tragedyayı incelerken, Platon'un incelemeleri diyaloglarına dağılmış durumdadır. Bütünsel bir felsefi sistemin içerisinde filozofların sanat, bilgi, varlık kuramlarının birbirleriyle göbekten bağı vardır. O hâlde, her şeyden önce, Platon'un sanatın içeriğine ilişkin eleştirisini anlamak için bilgi kuramının kısa bir anlatımı yapılmalıdır.

\section{Epistêmê-Dóksa}

Platon, görünüşlere dayalı olarak elde edilen bilgi türünü doksa olarak adlandırırken, akıl aracillğıyla diyalektik bir soruşturma sürecinden geçerek kavranan bilgi türünü epistêmê olarak adlandırır. Platon'un hakikat/gerçeklik bilgisi epistêmê ve sanı/görünüş bilgisi dóksa arasındaki ayrıma dayanan bilgi kuramını simgeleyen iki benzetmesi bulunmaktadır. Birincisi çizgi analojisi, ikincisi mağara alegorisi olarak bilinir. Platon, bilgi türleri olarak kavrayış, çıkarış, inanış ve sanı olarak belirlediği dört yolu, Devlet diyalogunda, bölünmüş çizgi analojisi ile anlatır. Bir çizgiyi, öncelikle (1) kavranan dünya ve (2) görülen dünya olarak ikiye böler. Kavranan dünyaya ilişkin bilgi kendi içinde (1a) aklın diyalektik gücüyle kavradığı şeyleri, ilke değil birer dayanak noktası yaparak tüm varsayımların üzerindeki bütünün ilkesine ilişkin bilgi e.d. kavrayış (1b) 2a'nın gölgelerini, varsayımlar olarak alarak ilkelere ulaşan bilgi e.d. çıkarış -Platon bu bölüme aritmetik, geometri vb. bilimleri koyar- olarak ikiye bölünür. Sanıya dayalı bilgi/dóksa de (2a) bu kavranan evrenin gölgeleri olan, görülür evrenin nesnelerine ilişkin bilgi e.d. inanış ve (2b) 2a'nın gölgelerini belirli parlak yüzeylerde -ayna, su vb.- yansımalarına ilişkin bilgi e.d. sanı olmak üzere ikiye bölünür (Platon, 1995: 196-198, 509a-511e). Yine Devlet diyalogunda bulunan meşhur mağara alegorisi de bilgi türlerini ayırmak üzere iş görür. Bir mağarada birtakım zincirlerle bağlı duran insanlar mağara girişini arkalarına alarak yüzleri duvara dönük otururlar, tam arkalarında ise büyük bir ateş yanmaktadır. Önlerindeki duvarda belirli imgeler gören, başlarını dahi kıpırdatamayan bu zincirli insanların dünya hakkında tek bildikleri şey bu imgelerdir, onlara verdikleri adlarla nesnelerin gerçekliğini anlattıklarını sanırlar. Aralarından biri zincirlerinden kurtulup mağaranın dışına çıkar ve duvardaki imgelerin aslında ateşin etkisi ile duvara yansıyan gölgeler olduğunu öğrenir. Gölgelerin ait oldukları nesneler mağaranın dışındadır. Öyleyse mağaradaki imgeler 'yalnızca gölgelerdir' 'gerçekler' değil. Platon, bu kişinin bu bilgiyle geri dönüp, o imgeleri gerçek kabul ederek yaşamaktansa Akhilleus gibi <fakir bir çiftçinin hizmetinde uşak olmayı > tercih edeceğini söyler. Üstelik geri dönse ve mağarada halen aynı şekilde zincirli bulunan insanlara bu deneyimini anlatma çabasında bulunsa, herkesin ona güleceğini, hatta sonunda öldürülebileceğini de ekler (Platon, 1995: 199-201, 514a$517 \mathrm{a})^{4}$

Platon iki benzetmeyi de bilgi kuramının temelinde duran epistêmêile dóksa ayrımını anlatmak için kullanır. Epistêmê, ilk hakikatleri, dóksa bu hakikatlerin gölgelerini ima eder. Epistêmê arayışını ifade eden diyalektik/diyalektikêe yürüyüss, bizzat Sokrates'in tartışma biçimi olan diyaloglar

\footnotetext{
${ }^{4}$ Platon'un aklında hocası Sokrates’in olması olağandır. Sokrates, epistêmê türü bilgi ile doksa türü bilgi arasındaki ayrımı yapabilmek için, toplumda yerleşik hâlde bulunan kanıları sorgulamak için özellikle toplum yönetiminde yer almayı planlayan gençlerle yaptığı sokak söyleşileri ile tanınır. Bu söyleşilerden ve elbette sorgulamalardan rahatsızlık duyanların suçlamaları sonucu idama mahkûm edilerek öldürülür.
} 
aracılığılla gelişir. ${ }^{5}$ Platon, kathareúô temiz veya saf olmak kökeninden gelerek, arıtma, arındırma, arınma, saflaş(tır)ma, temizle(n)me, boşal(t)ma anlamlarını taşıyan kátharsise ${ }^{6}$ ruhun diyalektik yürüyüşü aracillğıyla sağlanan düşünsel arınma anlamını yükler. "Bu öyle bir temizlemedir ki, dinleyiciye en büyük hazz1, hastaya da en devamlı faydayı sağlar" (Eflatun, 1988: 31, \$230c). Diyalektik sorușturmasında ruh, arınır, kátharsis gerçekleșir. ${ }^{7}$ Kátharsis, bu bağlamda, düșüncenin sanılardan arınması anlamını taşır. "Rivayet edildiğine göre (Iamblikhos, Peri pûth. 110), kátharsis, mousikê aracilığıyla etki altına alınan rûhun bir arınışı, yanî rûhu âhengli hâle getirmek sûretiyle rûhun bir arındırılışıdır; aslında bu arınma felsefedir" (Peters, 2004: 181). Ama Platon'un bilgi kuramının sanat eleştirisi ile bağlantısı nedir? Platon'un tarihsel deneyiminde yer tutan iki sanatın kesişim noktası olan dóksa üretici/aktarıcı etkileri bizi Platon'un genel olarak sanat, özel olarak ise tragedyaya yönelttiği eleştirinin içeriğine götürecek.

\section{Sofistin Tékhnêsi - Rhetorik}

Türkçede sanat kavramına karşıllk gelen tékhnê, Eski Yunan'da hem zanaat gibi el becerisine dayalı üretimleri hem de ressam, şair, ozan ve oyuncular tarafindan icra edilen etkinlikleri kapsayan geniş bir anlam içeriğine sahiptir. Sofist diyalogunda Platon, asıl hedefi gibi görünen 'sofisti arama ve yakalama ${ }^{8}$ yani sofistin bir sanatçı olup olmadığını sorgulama uğraşısında, önce sanatları araştırır. Sanatları meydana getirme ve elde etme sanatları olarak ikiye ayırır; çiftçilik, canlı bakımı, aletle üretilen her iş ve taklidi, önceden var olmayan bir şeyi, varlı̆̆a getirmiş olmaları dolayısıyla meydana getirme sanatları olarak sinıflandırır (Eflatun, 1988: 8, 219-a-b). Bilgi, savaş ve av sınıfindan para kazanmayı da, önceden var olan e.d. daha önce meydana getirilmiş olanları, bazen söz ve işle yakalamalarından ve bazen de yakalamak isteyene karşı korumalarından dolayı elde etme sanatları olarak sınıflandırır. Bu güzel diyalog, sanata ilişkin ayrımları belirlemelerle ve sofisti bir avcıya, sonra yürürler avcisı yani insan avcısına, oradan da insanları kandırma ile avlayan biri olarak tanımlamaya kadar sürer. Biz sofisti değil de sanatını aradığımız için bu diyalogu daha fazla irdelemeyelim. Platon'un eleştirisine muhatap olan sofistin sanatına yönelelim; retorik/rhetorike. ${ }^{9}$ Sokrates gibi Platon da sofisti hem para karşllı̆ı bilgi satan tüccarlar hem de bu ticareti retoriği kullanarak icra eden kişiler olarak sınıflar. Retorik, sanat olarak, bir bilginin edinilme değil, karşı tarafa aktarılma biçimidir. Bu biçim, karşı tarafın aktarılan bilgiye inanması için gerekli görülen tekniklerin tümüdür. Sofistlerin kullandıkları hitabet/söylev biçimi Platon'un yapısı itibarıyla da karşı çıktığı bir biçimdir. Platon'a göre diyaloglar karşılıklı akıl yürütme yoluyla bilgiyi arama imkânı sağlarken, söylev, tarafları söylevi veren ve alan kişi olarak böler ve dinleyiciyi edilgin bırakır, her türlü inanca, sanıya,

${ }^{5}$ Akıl yürütme, savlama, kanıtlama sanatı ve ilmi gibi anlamlar taşıyan bê diyalektikê ile seçmek, ayıklamak, akıl yürütmek, biriyle söyleşmek anlamlar taşıyan dialêgó arasındaki benzeşim ve Platon'un diyalektik kavramını kullanışının metinlerdeki farkl1lığı üzerine kısa bir özet için diyalektikê maddesi bkz. Peters, 2004: 65-66.

${ }^{6}$ Kátharsis maddesi için bkz. Peters, 2004: 180. Kátharsis, Platon için ruhun epistêmê yolunda sanılardan arınmasıyken, Aristoteles için duyguların arınması anlamını taşıyarak evrilir. Tragedya özelinde kátharsis Aristoteles şöyle tanımlar: "Bu taklit, anlatı yoluyla değil, eylem içindeki kișiler tarafından yapılır; uyandırdığı acıma ve korku aracılığıyla da, bu türden heyecanların katharsisini gerçekleştirir”" (Aristoteles 2003: 30). Bu anlam kayması büyük önem taşımakla birlikte, bu yazının dişındadır.

7 Sofistlerin döneme en büyük katkılarının bilgi, erdem, özellikle de siyasal bilginin ve erdemin doğuştan ve aristokratların kalıtımsal niteliği olduğu yönündeki genel kanıya karşı çıkmaları ve demokratik tutumu benimsemeleri olduğu belirtilir (Şenel, 2004: 131). Öte yandan, şunu belirtmeliyiz ki, sofistlerin düşüncelerini, bilgiyi talep edenlere satma yolundaki yöntemlerinin biçim ve içeriği, hem Sokrates hem Platon tarafindan karşı çıkılan şeyin kendisidir.

${ }^{8}$ Platon, yaşlılık dönemi diyaloglarından biri olarak belirlenen Sofist diyalogunda, sofistin sanatının nasıl bir sanat olduğunu soruşturur. Bu insanlar ne yapar? Satmak istedikleri bilgi, epistêmê yahut dóksa mıdır? Bu bilgilere kendileri sahip midirler? Bu bir sanat mıdır? Sanatsa nasıl bir sanattır? Toplumdaki işlevi nedir? gibi soruların izinden gider. Platon'un ironik deyişi ile sofisti yakalama, hem onu ve sanatını belirleme, hem de küçümseme anlamlarına gelir.

${ }^{9}$ Retorik, konuşma, söz söyleme anlamlarına gelen eirein kökeninden, etkileyici konuşma, söylev sanatını ifade eder. Platon'un toplumsal etkisini tespit ettiği retorik sanatının işlevinin elde var olan inandırma yollarını kullanma yetisi olduğunu daha sonra daha net bir ifadeyle Tékhnê Rhetorike metninde Aristoteles kaleme alacaktır (Aristoteles, 2012: 37). 
kandırmaya açık hale getirir. ${ }^{10}$ Sokrates'in diyalektik yürüyüşünü benimsemiş olan Platon'un yazılarını diyaloglar halinde kaleme alması, sofistlerin söylev biçimlerinin toplum üzerindeki etkilerine yönelik bir eleştirinin sonucudur. Platon için sofistlerin söylev biçimi olan retorik, bilginin arayışı olmaktan çok, birinin bilgisini bir diğerine aktarmasının ve inandırmasının aracı ise, retorik aracilığıyla oluşan bu bilgi türü epistêmê değil dóksadır. Bilgi kuramına bağlı olarak Platon'un eleştirisi, sofistlerin, retorik sanatını kullanarak hem aktardıkları bilginin türüne hem de aktarılan kişinin bu bilgiyi dolaysızca dışarıdan alarak ona inanış tarzına yöneliktir. Bu bilgi de hakiki bilgi olmayan bilgi e.d. dóksadir.

\section{Tragedyanın Tékhnêsi -Mimêsis}

Peki tragedya ve oyuncularıyla, retorik ve sofistler arasındaki bağ nedir? Bu bağı mimêsis kavramı ile kuracağı, yani taklit. Platon mimêsisi, genel olarak 'bir şeyi başka bir şeye benzetme uğraşısı' olarak tanımlar. Aristoteles'in ise taklidin ne olduğunu açıkça tanımlamadığı ancak yaygın kullanılan bir sözcük olarak Platon'dan aldığı söylenir (Ross, 2011: 320). Yine de Aristoteles’in sanat görüşündeki mimêsis kavramına yüklediği anlamın, Platon'un yüklediği anlamdan farklı olduğunu ifade eden kimi yorumlara rastlanır. Ayrım, Aristoteles'in taklide, terimsel kökeni poiein olan, yapmak, etmek, eylemek anlamlarına gelen poiêsis/yapma, biçimlendirme, oluşturma sanat ${ }^{11}$ olarak yaklaştı̆̆ından Platon'un ise taklidi düz bir yansıtma anlamında kullandığı noktasından yapilır. ${ }^{12}$ Oysa tıpk Aristoteles gibi Platon'un da Sofist diyalogunda taklidi, meydana getirme sanatı olarak sınıflandırdığını görürüz. Devlet diyalogunda ise işler biraz daha karışır görünür. Platon, düz anlatım ve mimêsis arasında bir ayrım gözetir; ozanlar ve şairler öyküleri üçüncü tekil şahıs olarak aktarırlarsa bu, taklide başvurmadan düz anlatmadır (Platon, 1995: 84, 394a). Ancak, kendileri -şairler- bir başkası yerine geçer, sözünü, sesini, davranışını bir başkasının kişiliğine uydurursa benzemek istediği kişiyi taklit etmiş olur. Bu da mimêsistir (Platon, 1995: 84, 393 c). Aristoteles'in de eylem ile mimêsis ve anlatı yoluyla mimêsisi ayırdığını görürüz. Tragedya, taklidin anlatı yahut destan yoluyla değil, eylem yoluyla gerçekleştirilmesidir; "bu taklit, anlatı yoluyla değil, eylem içindeki kişiler tarafindan yapılır; ..." (Aristoteles, 2003: 30). Burada anlatı yoluyla taklit, herhalde Platon'un Homeros'u, şairin kendini gizlemesi ve birinci şahısmış gibi olayları aktarmasını eleştirdiği durumu da kapsar (Platon, 1995: 84, 393d). Aslında bir karışıklık yoktur; Platon için mimêsis birinin başka birinin k1lığında olması, söz, ses ve davranış ile taklit etmesidir, bu bir meydana getirme olsa, mimêsis de meydana getirme sanatları içerisinde yer alsa bile. Yani bu meydana getirme etkinliği, gerçek olan değil, öykünün gerçekmiş gibi görünmesine yol açtı̆̆ tespit edilen üçüncü şahsın birinci şahıs dilini kullanması ile ortaya çıkan mimêsistir. Platon'un yerdiği mimêsis, öncelikli olarak burada biçim gibi görünür. Oysa Platon, devlet yöneticilerinin neden kötüyü korkan, sövüp sayan, alay eden kişileri vs...- taklitten uzak durmaları gerektiğini açılarken vurguladığı ifade açıtır; “... çünkü taklit ede

\footnotetext{
10 Sofistler kişilerin kendi sorgulama ve öğrenme çabalarını genel olarak yersiz görüyorlardı, retorik, diyalektik ile karşılaştırıldığında, genel kanıların ya da başka bir biçimde söylersek başkalarına dair fikirlerin aktarılmasından ve diğerlerine inandırıcı bir söyleve bürünmesinden ibaret kalan bir biçimdir. Hatta "bazı sofistler, insanın hiçbir şey öğrenemeyeceğini savunuyorlardı" (Thomson, 1988: 381).Yüzyıllar sonra Bertolt Brecht (1898-1956) bu manada izi sürülebilir bir eleştiri ile oyunun toplumsal etkilerini dikkate alarak tiyatroda yeni bir yöntem geliştirecektir; epik tiyatro. Bu konuda yapmıș olduğum bir inceleme için bkz. Eker, 2015.

11 Poiein maddesi için bkz. Peters, 2004: 307.

${ }^{12} \mathrm{Bu}$ türden bir yorum için bkz. (Yetişken, 2012: 29). Aristoteles ile Platon arasındaki taklide ilişkin temel bakış açısı farklılı̆̆ı, ikisinin bu sanata farklı amaçlar yüklemiş olmalarından ileri gelir. Aristoteles, tragedyanın amacını duyusal katharsis olarak belirlerken, tragedyanın konu içeriğinin gerçeklik düzeyini tartışmaz. Çünkü ona göre tragedyanın amacı, gerçek bilgi vermek yahu bu bilgiye giden yolu soruşturmak değildir. İnsanları inandırma yoluyla amacını gerçekleştirmesi, yani duyusal katharsis sağlaması yeterlidir. “... şiirde 'olanaksız’ görünen şeyler, bir biçimde açıklanabilmelidir. Ya güzelleştirme çabasıyla ya da genel kanıya uygunlukla. Şiirde inandırıcı olan olanaksız bir şey, inandırıcı olmayana -olanaklı bile olsa- yeğlenmelidir. Zeuksis'in resmettiği gibi insanların var olması besbelli olanaksızdır; ama o ereğe uygun resmetmiştir onları; ereğe uygun olanın da var olandan üstün olması gerekir" (Aristoteles 2003: 75).
} 
ede, sonunda taklit ettikleri şeye alışırlar. Bu alışkanlık da bedeni, konuşmayı, görüşleri değiştiren ikinci bir tabiat olur" (Platon, 1995: 86-87, 395c-396e). Onlar1 iyiye -yiğitlik, bilgelik gibi erdemler vs.- götüren taklidi ise yine mimêsis etkinliği olsa bile bu kez etkileri iyi olacağından, yapabilirler, iyi bir kimsenin taklidini yaparken, bu taklitten utanmaz ve kendisi o adammıs gibi davranır daha doğru bir ifadeyle davranabilir (Platon, 1995: 86-87, 395c-396e). Şimdi daha net bir ayrim koyabiliriz; Platon'un eleştirisi, şiir ve tragedyadaki mimêsisin biçimsel yapısına değil, mimêsis ile aktarılan bilginin gerçek olmamasınadır. Mimêsisteki dóksa sanatçının e.d. üçüncü şahsın kendini birinci şahıs yerine koyması yoluyla, etki olarak da izleyiciyi buna inandırması yoluyla iki türlü ortaya çıkar. Dóksa aktarılan bilgi olarak hem aktaran hem de aktarılan kişiyi didaktik açıdan da etkiler ve gerçekten uzaklaştırır. O hâlde yine bilgi kuramına bağlı olarak Platon için sorun, biçimsel yönden tragedya ya da şiir değil, tragedya oyuncularının taklidi kullanarak aktardıkları bilginin türüdür. Çünkü bu kandırma, gerçek öyle olmasa bile bazı şeyleri gerçekmiş gibi ifade ederek, toplumu da etkiler. Örneğin, kahramanların değersiz olduklarının, tanrıların kötülük yapanlar olarak toplum içerisinde anlatılması ve gerçekliğinin kabul edilmesi insanoğlunun yapacağı tüm kötülükleri haklı çıkaracak zemin bulmasına olanak sağlar (Platon, 1995: 81-82, 391d-e). Bu bilgi de, yine retoriğin aktardığ1 bilgi türü gibi, hakiki olmayan bilgi e.d. dóksadır.

\section{Son Söz Yerine}

Platon, felsefi ereğini epistéméye yönelen bir toplum olarak belirler ve mimêsis ve retorik aracıllı̆̆ıla gerçekleşen/yaratılan sanatları bu amaca yönelik etkileri bakımından inceler. Tarihsel deneyimi içerisinde iki etkinlikle de karşı karşıya kalan Platon’un eleştirisi, dóksa türü bilgiyedir. ${ }^{13}$ Hem sofist hem de tragedya oyuncusu tarafından farklı biçimlerde de olsa aktarılan bu bilgi türü, izleyici ya da dinleyici tarafından gerçek olarak algılanır. Platon, doğrunun çok olduğunu ve sanatların işlevlerinin farklı olsa da (olumsal nitelikleri göz önünde bulundurulduğunda ve didaktik etkileri göz önünde bulundurulduğunda, bunun onun tarafından kabul edildiği görülür) amaçlarının farklı olduğunu kabul edemezdi. Ona göre ruhun epistêmê yolunda sanılanndan arınması/ kátharsisi ancak diyalektik ile mümkündü. Kesin ve hakiki bilgi, tüm varsayımların üzerindeki bütünün ilkesine ilişkin bilgi e.d. kavrayış basamağında tektir. Amaç da bu bilginin arayışı olarak tek olandır ve bütün bilimler bu yöne doğru basamaklandırılır.

İki sanatsal biçim; retorik ve tragedya. İki sanatın ortak noktası dóksa. Dóksa, bir bilgi türü, içerik. Platon eleştirisini, bu sanat biçimlerine olmaktan çok içeriklerine yöneltir. Öyleyse, çalışmamızı kendimize ve okuyucuya yeni sorular doğuracak olan sorular birakarak tamamlayalım. Taşıdığ1 içeriğe ilişkin bir tikel sanat türünü eleştirmekle, genelinde sanatsal etkinliği eleştirmek aynı değeri mi taşır? Aktardığı içeriğin mahiyeti dikkate alınmadan "ne olursa olsun" sanat türü olarak ortaya çıkan her etkinliği olumlamaması Platon'u sansürcü ya da sanat düşmanı yapar mı? Dóksaya dóksa, gölgeye gölge diyebilmenin imkânm yok saymayan bir eleștiri daba aymntıl ve dikkatli bir göz̆lemle nasıl kurulabilir? Daha da büyük bir soru ile noktalayalm; dóksayn dóksa yapan epistémé ile gölgeyi gölge yapan güneş/ateş/ ışı. bugün nerededir?

\section{Kaynakça}

AĞAOĞULLARI, Mehmet Ali (2009). Kent Devletinden Imparatorluğa, Ankara: İmge Kitabevi Yayınları.

ARİSTOTELES (2003). Poetika, çev. Samih Rifat, İstanbul: Küçük Kitaplar.

ARİSTOTELES (2012). Retorik, çev. Mehmet H. Doğan, İstanbul: Yap1 Kredi Yayınları.

\footnotetext{
${ }^{13}$ Sofist diyalogunda, her türlü şekli ile musiki, resim, hokkabazlık, ister eğlence ister ciddi inceleme konusu olarak taşınan ve satılan niteliğe sahip mallar satanı da tüccar diye sınıflandırır Platon. O hâlde tragedya oyuncusu ve sofist arasında, Platon'un eleştirisi kapsamında ikinci bir bağ da bulunmaktadır; dóksa düzeyinde kalan bilgi, ikisi için de bir ticaret nesnesi olarak kullanılmaktadır.
} 
EKER, Hatice İrem (2021). “Platon Felsefesi’nde Sanat Eleştirisine Giden Yol ya da Gölgeye Gölge Diyebilme İmkânı”, Mavi Atlas, 9(1): 171-177

EFLATUN (1988). Sofist, çev. Mehmet Karasan, İstanbul: MEGSB Yayınları.

EKER, İrem H. (2015). "Sanata Marksist Bir Yaklaşım Olarak Bertolt Brecht Tiyatrosu” içinde Marksist Estetik, Felsefelogos, 2015-4, Say1: 59, ss. 63-80.

PETERS, Francis E. (2004). Antik Yunan Felsefesi Terimleri Söælï̈ğ̈, çev. Hakk1 Hünler, İstanbul: Paradigma Yayınları.

PLATON, (1995). Devlet, İstanbul: Remzi Kitabevi.

ROSS, David (2011). Aristoteles, çev Ahmet Arslan, İstanbul: Kabalcı Yayınevi.

ŞENEL, Alâeddin (2004). Siyasal Düş̈̈nceler Taribi, Ankara: Bilim ve Sanat Yayınları. Yayınları.

THOMSON, George (1988). İlk Filozoflar, çev. Mehmet H. Doğan, İstanbul: Payel

YETISSSKEN, Hülya (2012). “Aristoteles’te Sanatın Neliği ve İşlevi” Kaygı Dergisi, 19, ss. 2735. 